\title{
Hierarchical Assembly of Model Cell Surfaces: Synthesis of Mucin Mimetic Polymers and their Display on Supported Bilayers
}

\author{
David Rabuka ${ }^{1}$, Raghuveer Parthasarathy ${ }^{1}$, Goo Soo Lee ${ }^{1,4}$, Xing Chen ${ }^{1}$, Jay T. \\ Groves $^{1,4}$, and Carolyn R. Bertozzi ${ }^{1,5}$ \\ 1 Department of Chemistry, University of California, Berkeley, California 94720. \\ 2Department of Molecular and Cell Biology, University of California, Berkeley, California 94720. \\ 3Department of Hughes Medical Institute, University of California, Berkeley, California 94720. \\ 4Materials Sciences Division, Lawrence Berkeley National Laboratory, Berkeley, California 94720. \\ 5The Molecular Foundry, Lawrence Berkeley National Laboratory, Berkeley, California 94720.
}

\begin{abstract}
Molecular level analysis of cell surface phenomena could benefit from model systems comprising structurally-defined components. Here we present the first step toward bottom-up assembly of model cell surfaces - the synthesis of mucin mimetics and their incorporation into artificial membranes. Natural mucins are densely glycosylated O-linked glycoproteins that serve numerous functions on cell surfaces. Their large size and extensive glycosylation makes the synthesis of these biopolymers impractical. We designed synthetically tractable glycosylated polymers that possess rod-like extended conformations similar to natural mucins. The glycosylated polymers were endfunctionalized with lipid groups and embedded into supported lipid bilayers where they interact with protein receptors in a structure-dependent manner. Furthermore, their dynamic behavior in synthetic membranes mirrored that of natural biomolecules. This system provides a unique framework with which to study the behavior of mucin-like macromolecules in a controlled, cell surface-mimetic environment.
\end{abstract}

\section{Keywords \\ Carbohydrates; Glycopeptides; Mucins; Polymers [bio(org).]; Supported lipid bilayer; FRAP}

\section{Introduction}

Cell surface phenomena have been largely refractory to molecular level analysis due to the highly complex and dynamic nature of the cell membrane and its associated biopolymers. Efforts to understand how cell surface molecules guide interactions with other cells and extracellular matrix components could benefit tremendously from structurally-defined synthetic model systems. The bottom-up fabrication of such systems begins with the identification of prevalent cell surface-associated molecules and the generation of membranebound mimetics that retain biological function.

AUTHOR EMAIL ADDRESS crb@berkeley.edu.

Supporting Information Available: Synthetic procedures for compounds 1-3 and 9; IR, ${ }^{1} \mathrm{H}-\mathrm{NMR}$, GPC spectral data for compounds 1-3, 5-7; TEM image of 3; ${ }^{1} \mathrm{H}-\mathrm{NMR}$ spectral data for compounds 10-14 and 17-20; binding of FITC-HPA to supported bilayer. This material is available free of charge via the Internet at http://pubs.acs.org. 
Mucins are part of the cell-surface glycoprotein repertoire modulating critical cell-cell interactions. ${ }^{1}$ They are characterized by extended regions of densely clustered serine (Ser) and/ or threonine (Thr) residues bearing O-linked glycans that initiate with $\alpha$-linked $N$ acetylgalactosamine (GalNAc) (Figure 1A). The closely packed glycans force the polypeptide backbone into an extended structure, giving mucin molecules a rod-like shape. ${ }^{2}$ As a consequence, membrane-associated mucins are believed to tower above the surrounding glycocalyx where they are poised to mediate interactions with other biomolecules and cognate cells. Mucins are known to participate in cell adhesion events associated with diseases such as chronic inflammation ${ }^{3}$ and cancer metastasis. ${ }^{4}$ Secreted mucins, like those forming the major constituents of mucus, have unusual viscoelastic properties and can passivate epithelial cell surfaces. ${ }^{5}$ These features have suggested possible roles for mucin-like molecules as biocompatible coatings for synthetic materials. ${ }^{6}$

As a first step in the generation of model cell surfaces, we have focused on the synthesis of mucin-like molecules that can be displayed on model membranes. Small mucin glycopeptide fragments have been generated by several groups using solid-phase peptide synthesis methods.

${ }^{7}$ However, the adaptation of such methods to larger, more biologically relevant mucin molecules is not straightforward. To date, the largest full-length mucin glycoprotein constructed using synthetic methods is GlyCAM-1, a rather small polypeptide of 132 residues. 8 The construction of the peptide required a combination of solid-phase glycopeptide synthesis and protein ligation techniques and is not amenable to the generation of analogs tailored for specific applications. Thus, we directed our attention to the design of mucin mimics that possess the key structural and biological features of native glycoproteins but can be prepared more efficiently.

The dense glycan clusters of mucin glycoproteins are responsible for both their extended rodlike structures and hydrodynamic properties. However, biophysical studies using native mucins have shown that the glycans can be trimmed down to single peptide-bound GalNAc residues without significant loss of structure. ${ }^{9}$ 2-D NMR analysis of synthetic mucin fragments containing only six amino acid residues and a cluster of $\alpha$-linked GalNAc residues revealed a highly structured and extended polypeptide backbone, consistent with a critical role for the core GalNAc residues in governing the overall structure of the mucin biopolymer. ${ }^{10}$

Guided by these observations, we synthesized mucin mimetics comprising a long, synthetically tractable polymer backbone decorated with $\alpha$-linked GalNAc residues intended to impart backbone rigidity (Figure 1B). The glycan clustering was designed to create unfavorable steric interactions that would be minimized when the polymer chain is fully extended. The oxime linkage by which the sugars are attached to the polymer can be assembled by chemoselective ligation 11 of the corresponding ketonefunctionalized polymer $(\mathbf{1}-\mathbf{3})$ with the two anomers of aminooxy GalNAc analog $4 \boldsymbol{\alpha}^{12}$ (Figure 1C). Any aminooxy sugar can be ligated to the polymer backbone in this fashion, including the $\beta$-anomer of aminooxy GalNAc (4;). This convergent process permits facile modification of either the polymer or sugar components, allowing for the efficient generation of numerous mucin analogs. In this study, we generated mucin mimetics with various polymer backbones derived from methyl vinyl ketone (MVK) (1 and 2, Figure 1C) or isopropenyl methyl ketone (IMK) (3) combined with the water-solubilizing monomer $N$-[3-(dimethylamino)propyl]-acrylamide (DAPA). ${ }^{13}$ Both MVK and IMK introduce ketones into the polymer backbone, but poly(IMK) has additional backbone substitution that we reasoned might contribute to overall rigidity.

With the ultimate goal of constructing model cell surfaces, we further synthesized endfunctionalized glycopolymers that insert into lipid bilayers thereby mimicking membranebound mucin glycoproteins. These polymers were adorned with various hydrophobic tail groups, including cholesterol, single chain lipids, and phospholipids. ${ }^{14}$ Biophysical 
characterization of the bilayer-associated mucin mimetics indicated fluid mobility similar to membrane-associated proteins. Finally, we demonstrated that bilayer-associated mucin mimetics can bind specifically to protein receptors. This system provides a novel platform with which to study cell surface interactions using structurally-defined components.

\section{Results and Discussion}

\section{Synthesis and characterization of mucin mimetic polymers}

We prepared poly(MVK) (1), ${ }^{13}$ co-poly(MVK/DAPA) (2), ${ }^{15}$ and co-poly(IMK/DAPA) (3)

16 by radical-induced polymerization using literature procedures. Copolymers 2 and $\mathbf{3}$ were generated using 4.4 equivalents of MVK or 5.0 equivalents of IMK, resulting in copolymers with similar monomer ratios (Scheme 1, 4.7 MVK or IMK:DAPA based on elemental analysis). $\alpha$-Aminooxy GalNAc (4a) was prepared using our previously reported procedure. 12 The polymers were combined with compound $\mathbf{4} \boldsymbol{\alpha}$ ( $2-3$ equivalents per ketone) in water with $0.1 \% \mathrm{AcOH}$ for 96 hours at $95^{\circ} \mathrm{C}$, then dialyzed to remove unreacted sugar. In the case of poly(MVK), acetonitrile (75\%) was used as a co-solvent. The GalNAc-conjugated polymers 5, 6, and 7 (Scheme 1) were lyophilized and characterized by IR and NMR spectroscopy, gel permeation chromatography (GPC), and elemental analysis.

In order to determine the extent of ketone ligation, we measured the change in apparent molecular weight $\left(\mathrm{M}_{\mathrm{w}}\right)$ of the polymers after reaction with compound $\mathbf{4} \boldsymbol{\alpha}$ using GPC. The $\mathrm{M}_{\mathrm{w}}$ ratio of GalNAc-conjugated 5 to unmodified poly(MVK) (1) was found to be 3.96 (Table 1). The theoretical $\mathrm{M}_{\mathrm{w}}$ ratio corresponding to $100 \%$ ketone conjugation was calculated to be 4.11. Thus, the chemoselective ligation reaction was nearly quantitative. Analysis of polymers $\mathbf{6}$ and $\mathbf{7}$ yielded similar results.

In order to determine the consequences of sugar clustering on the overall structures of the polymers, we compared the effective hydrodynamic diameters $\left(D_{h}\right)$ of the GalNAc-conjugated and unmodified polymers using dynamic light scattering. The light scattering behavior of each polymer was fitted to that of an equivalent sphere. No corrections for non-spherical shape were made as the expected difference between extended and globular polymers is large. ${ }^{9}$ The measured $\mathrm{D}_{\mathrm{h}}$ values for the unmodified polymers $\mathbf{1}, \mathbf{2}$, and $\mathbf{3}$ were $1.9,2.0$, and $2.1 \mathrm{~nm}$, respectively. Given the apparent molecular weights of 18330, 32500, and 29690, respectively, derived from GPC data (Table 1), these $D_{h}$ values indicate a globular structure. $\left(D_{h}\right.$ was measured in THF for $\mathbf{1}$, and in water for $\mathbf{2}$ and $\mathbf{3}$; solubility limitations prevented $D_{h}$ measurements for $\mathbf{1}$ in water.) The $\mathrm{D}_{\mathrm{h}}$ values of the GalNAc-conjugated polymers $\mathbf{5}, \mathbf{6}$, and 7 were 54.0, 54.7, and $65.0 \mathrm{~nm}$, respectively, implying a more extended structure. The theoretical fully-extended lengths of $\mathbf{5 , 6}$, and $\mathbf{7}$ were calculated ${ }^{17}$ to be $66.8,95.8$, and 78.5 $\mathrm{nm}$, respectively (Table 1 ). By comparing these values to the measured $\mathrm{D}_{\mathrm{h}}$ values for the GalNAc-conjugated polymers, we estimated the percent extension of the polymer backbones to be $81 \%$ for $\mathbf{5}, 57 \%$ for $\mathbf{6}$, and $83 \%$ for $\mathbf{7}$. Thus, the rigidification imposed by glycosylation was more significant for polymers 5 and $\mathbf{7}$ than for polymer $\mathbf{6}$. Polymer 5 lacks DAPA monomers and therefore possesses a higher density of GalNAc residues, while methylation of the backbone in $\mathbf{7}$ might add steric bulk and restrict conformational freedom. In all three cases, GalNAc clustering on the polymer backbone led to a more extended conformation, similar to what is observed with native mucins.

The configuration of the mucin mimetics was further assessed by transmission electron microscopy (TEM) analysis of polymer 5 (Figure 2). Individual polymer molecules could be seen as rods with lengths of $20-80 \mathrm{~nm}$, consistent with the light scattering data. Thus, based on both light scattering and TEM data, we conclude that the GalNAc-conjugated polymers adopt an extended configuration while the parent, non-glycosylated polymers, do not. 


\section{Modular synthesis of end-functionalized mucin-mimetic polymers}

The application of these mucin mimetic polymers as model systems for cell surface studies or as coatings for biomaterials required their end functionalization with moieties that can associate with hydrophobic or amphiphilic surfaces. Toward this end, we first generated two lipidmodified AIBN derivatives, 8 and $\mathbf{9}$ (Figure 3), for use as radical initiators. ${ }^{18}$ The compounds were prepared by EDC-mediated coupling of octadecylamine or cholesterol, respectively with 4,4'-azobis(4-cyanovaleric acid) (ACVA). Heating the free radical initiators in the presence of MVK at $95^{\circ} \mathrm{C}$ for $72 \mathrm{~h}$ afforded the end-functionalized keto-polymers $\mathbf{1 0}$ and $\mathbf{1 1}$ (Scheme 2). Compound $\mathbf{4} \boldsymbol{\alpha}$ was coupled to the keto-polymers to generate oxime-linked glycopolymers $\mathbf{1 2}$ and 13, bearing octadecyl and cholesteryl groups, respectively (Scheme 3). For biophysical studies, we also generated an octadecyl-functionalized glycopolymer bearing a small percentage of the fluorescent dye Texas Red. This was accomplished by coupling keto-polymer 10 with a mixture of compound $\mathbf{4} \boldsymbol{\alpha}$ ( 2.8 equiv) and Texas Red hydrazide ( 0.03 equiv), affording fluorescent mucin mimetic 14 (Scheme 3).

In preliminary experiments, we attempted to integrate lipid-terminated mucin mimetic 14 into synthetic lipid bilayers that were generated using previously described techniques. ${ }^{19}$ Briefly, two-dimensionally fluid, solid-supported membranes were formed on $\mathrm{SiO}_{2}$ substrates by standard vesicle fusion techniques. Polymer $\mathbf{1 4}$ was incubated with the lipid membranes at a concentration of $20 \mu \mathrm{g} / \mathrm{mL}$ for 15 hours. However, fluorescence microscopy analysis indicated that only a small amount of polymer incorporated into the membrane, which was insufficient for subsequent studies. Similar results were obtained with the analogous cholesterylfunctionalized polymer. Nonetheless, octadecyl-terminated mucin mimetics 13 and $\mathbf{1 4}$ proved useful as coatings for carbon nanotubes ${ }^{20}$ and have since been used to interface the nanotubes with live cells. ${ }^{21}$

In order to enhance the incorporation of mucin mimetics into supported bilayers, we sought to increase the lipophilicity of the end groups. Accordingly, we designed a second-generation end-functionalized polymer with a phospholipid tail that is more similar to biological membrane components. EDC-mediated coupling of ACVA with dipalmitoylphosphatidylethanolamine (DPPE) was unsuccessful. Thus, we converted ACVA to the bis-pentafluorophenyl (PFP) ester 15, which was directly coupled with DPPE. The bisDPPE AIBN analog 16 could not be isolated and was carried on directly to the polymerization reaction. Heating compound $\mathbf{1 6}$ in the presence of MVK at $95{ }^{\circ} \mathrm{C}$ for 72 hours afforded the end-functionalized polymer 17 (Scheme 4). As accomplished previously, compound $\mathbf{4} \boldsymbol{\alpha}$ was coupled to the polymer along with a small amount of Texas Red hydrazide to afford polymer 18. In parallel, we generated a similar polymer adorned with the $\beta$-anomer of GalNAc (19) by coupling compound $\mathbf{4 \beta}$ (Figure 1C) with keto-polymer 17 (Scheme 5).

Glycan elaboration of the keto-polymer backbone is not limited to simple monosaccharides. Taking advantage of the modular polymer design, we elaborated the end-functionalized polymer 17 with $\beta$-aminooxy- $N$-acetyl lactosamine ( $\beta$-aminooxy LacNAc). ${ }^{22}$ Using the conditions established for $\mathbf{4} \boldsymbol{\alpha}$ and $\mathbf{4 \beta}, \beta$-aminooxy LacNAc was coupled to $\mathbf{1 7}$ with a small amount of Texas Red hydrazide to afford polymer 20 (Scheme 5).

\section{Incorporation of mucin mimetics into fluid lipid bilayers}

Phospholipid-functionalized polymers $\mathbf{1 8}$ and $\mathbf{1 9}$, which differ only in the anomeric linkage of the pendant GalNAc residues, and polymer 20, containing LacNAc residues, were incubated with supported bilayers for 15 hours at a concentration of $20 \mu \mathrm{g} / \mathrm{mL}$, and the unbound polymer was removed by washing (shown schematically in Figure 4A). Fluorescence analysis indicated robust association with the supported bilayers, in stark contrast to the single lipid chain analog 14 discussed above. Fluorescence quantitation of the Texas Red-labeled glycopolymers gave 
an estimated density of around 500 molecules $/ \mu \mathrm{m}^{2}$ in the supported bilayer. In a control experiment, we bound polymer $\mathbf{1 8}$ directly to a glass substrate lacking a supported bilayer. In this case, the observed polymer density was only 20 molecules $/ \mu \mathrm{m}^{2}$, barely above the detection limit of our fluorescence microscope, indicating that adsorption to the underlying substrate is minimal.

Lateral mobility is a characteristic feature of biological membrane-associated proteins that permits the dynamic formation of functional complexes and aggregates. To address the biological relevance of our synthetic model system, we investigated the mobility of the membrane-bound mucin mimetics using the fluorescence recovery after photobleaching (FRAP) technique. ${ }^{23}$ Supported bilayers incorporating polymer 18 were irradiated with 560 $\mathrm{nm}$ light for 10 seconds and was monitored over several minutes (Figure 4B). This experiment yielded a diffusion coefficient for the mucin mimetic 18 of $2.7 \pm 1.5 \mu \mathrm{m}^{2} / \mathrm{s}$. Polymers 19 and $\mathbf{2 0}$ behaved similarly to $\mathbf{1 8}$ in all regards.

In parallel, we determined the intrinsic lipid mobility of the membranes by measuring the diffusion coefficient of Texas Red-modified 1,2-dihexadecanoyl-sn-glycero-3-

phosphoethanolamine using the FRAP method. The measured value of $2.3 \pm 0.8 \mu \mathrm{m}^{2} / \mathrm{s}$ was similar to that of the mucin mimetic, suggesting that polymer 18 was anchored to the membrane solely by its lipid moiety and not via strong lipid-sugar interactions. To our knowledge, this is the first report of mobile polymers anchored to a supported lipid bilayer.

\section{Interaction of membrane-associated mucin mimetics with proteins}

A major function of cell-surface mucins is to guide interactions among cells via specific molecular recognition by carbohydrate-binding proteins. We therefore assessed the ability of mucin mimetics 18 and 19 to bind carbohydrate- binding proteins (i.e., lectins) while presented on supported bilayers. Helix Pomatia agglutinin (HPA) is known to specifically bind $\alpha$-linked GalNAc residues but does not interact significantly with the $\beta$-anomer. ${ }^{24}$ Conversely, Bauhinia Purpurea agglutinin (BPA) binds to $\beta$-linked GalNAc residues, but not to the $\alpha$ anomer. ${ }^{25}$ Both lectins are available in fluorescein isothiocyante (FITC)-labeled form.

Supported lipid bilayers containing Texas Red-labeled mucin mimetics 18 or 19 ( 500 molecules $\left./ \mu \mathrm{m}^{2}\right)$, or no polymer, were incubated with FITC-labeled lectin $(30 \mu \mathrm{g} / \mathrm{mL}, 60$ minutes), which had been filtered prior to incubation, and then washed to remove unbound protein. The membrane-associated fluorescence derived from FITC or Texas Red was quantified by microscopy, and the ratios of these fluorescence intensities were compared for each lectin (Figure 5A). The amount of HPA bound to membranes bearing polymer $\mathbf{1 8}(\alpha-$ GalNAc/MVK) was significantly higher (8-fold) than that bound to membranes with polymer 19 ( $\beta$-GalNAc/MVK). Conversely, the amount of BPA bound to membranes presenting polymer 19 exceeded that bound to membranes displaying polymer 18 by 36 -fold. Bilayers with no associated mucin mimetics showed no detectable lectin binding (not shown). Thus, the specificities of the lectins as determined in biological systems are accurately recapitulated in this biomimetic system.

Supported lipid bilayers containing Texas Red-labeled polymer $\mathbf{2 0}$ were also probed for lectin binding activity using FITC-conjugated Erythrina cristagalli agglutinin (ECA), which is known to bind the LacNAc motif. ${ }^{26}$ As shown in Figure 5B, FITC-ECA labeled these bilayers with a 30 -fold stronger signal than observed with FITC-HPA.

\section{Conclusions}

In summary, the mucin mimetic polymers described here possess structural features similar to natural mucins but are far more synthetically tractable. With appropriate lipid end- 
functionalization, the polymers can be incorporated into fluid lipid bilayers where they demonstrate mobility similar to natural membrane-associated biomolecules. Finally, the mucin mimetics interact with carbohydrate-binding proteins in a specific fashion.

The repertoire of cell surface glycans is known to change during cell differentiation and malignant transformation. ${ }^{27}$ Notably, the sugar substituents on our mucin mimetics can be readily altered by chemical methods or elaborated enzymatically to provide a range of glycan structures that reflect various cell states. Thus, the system may be amenable to fundamental studies of cell surface interactions relevant to stem cell differentiation or metastasis.

Although prevalent on cell surfaces, mucins are only one component of a diverse landscape that includes thousands of additional protein and lipid molecules. Thus, the model cell surfaces generated in this study represent early intermediates in the bottom-up assembly of multifunctional surfaces that act as a complex system. Integration of additional biomolecules into this system is a current goal.

\section{Experimental Methods}

\section{General Methods}

All chemical reagents were of analytical grade, obtained from commercial suppliers, and used without further purification unless otherwise noted. 1,2-Dioleoyl-glycero-3-phosphocholine (DOPC) and 1,2-dioleoyl-3-trimethylammonium-propane (DOTAP) were purchased from Avanti Polar Lipids. 1,2-dihexadecanoyl-glycero-3-phosphoethanolamine conjugated to the fluorophore Texas Red (Texas Red DHPE) was purchased from Invitrogen. The fluoresceinconjugated lectins Helix Pomatia agglutinin (HPA), Bauhinia Purpurea agglutinin (BPA), and Erythrina cristagalli agglutinin (ECA) were purchased from EY Laboratories (San Mateo, CA). Flash chromatography was performed using Merck 60 Å 230-400 mesh silica gel. Analytical thin layer chromatography (TLC) was performed on glass-backed Analtech Uniplate silica gel plates, and compounds were visualized by staining with phosphomolybdic acid, $10 \% \mathrm{H}_{2} \mathrm{SO}_{4}$ in ethanol, and/or the absorbance of UV light. All reaction solvents were distilled under a nitrogen atmosphere prior to use. $\mathrm{CH}_{2} \mathrm{Cl}_{2}$, pyridine, and toluene were dried over $\mathrm{CaH}_{2}$. Unless otherwise specified, all solvents were removed under reduced pressure using a rotary evaporator. ${ }^{1} \mathrm{H}-\mathrm{NMR}$ and ${ }^{13} \mathrm{C}-\mathrm{NMR}$ spectra were obtained at 400 and $100 \mathrm{MHz}$, respectively, using a Bruker AVQ-400 spectrometer. Chemical shifts are reported in parts per million (ppm) relative to tetramethylsilane, and coupling constants $(J)$ are reported in hertz $(\mathrm{Hz})$. Infrared (IR) spectra were obtained using a Perkin-Elmer 1600 Series Fourier transform infrared spectrometer (FTIR). Low and high resolution fast atom bombardment (FAB) mass spectra were obtained at the UC Berkeley Mass Spectrometry Laboratory. Electrospray ionization (ESI) mass spectra were obtained with a Hewlett Packard Series 1100 mass spectrometer. Gel permeation chromatography (GPC) with THF as an eluent was carried out using a system composed of a Waters 510 pump with a Waters 717 auto sampler, 500 A PLgel columns thermostated at $35^{\circ} \mathrm{C}$, and an Optilab DSP differential refractometer thermostated at $35^{\circ} \mathrm{C}$. The GPC data were analyzed using Empower software (Waters) based on polystyrene and polysaccharide standards to calculate the polydispersity (PDI). TEM images were obtained on a FEI Tecnai $12120 \mathrm{KV}$ microscope operating at electron energy of $100 \mathrm{keV}$. Samples were prepared by depositing an aqueous solution $(0.05 \mathrm{mg} / \mathrm{mL})$ onto carbon-coated copper grids. The solution was allowed to absorb on the grids for $2 \mathrm{~min}$ followed by staining the material with $1.0 \%$ phosphotungstic acid.

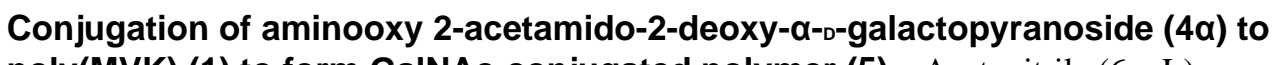
poly(MVK) (1) to form GalNAc-conjugated polymer (5)-Acetonitrile $(6 \mathrm{~mL})$ was introduced into a $25-\mathrm{mL}$ flask containing poly(MVK) (1) $(11.6 \mathrm{mg}, 0.165 \mathrm{mmol}$ based on carbonyl number) and $\mathbf{4 \alpha}^{12}(77.9 \mathrm{mg}, 0.330 \mathrm{mmol})$. Aqueous acetic acid $(0.5 \%, 2 \mathrm{~mL})$ was 
added to the mixture in order to dissolve compound $\mathbf{4} \boldsymbol{\alpha}$. After heating at reflux for $24 \mathrm{~h}$, the reaction mixture was allowed to cool to rt. All solvents were removed in vacuo, and then deionized water $(2 \mathrm{~mL})$ was introduced into the mixture to dissolve the partially ligated watersoluble polymer. After heating at reflux for $24 \mathrm{~h}$ to effect full ligation, the reaction mixture was cooled to rt, dialyzed against water to remove excess compound $\mathbf{4} \boldsymbol{\alpha}$, neutralized with Dowex 50WX8-100 resin and lyophilized to afford $\mathbf{5}$ as a fluffy white solid. ${ }^{1} \mathrm{H}-\mathrm{NMR}\left(\mathrm{D}_{2} \mathrm{O}\right.$, $\delta / \mathrm{ppm}$, see Figure SI-1b); IR (KBr, cm $\left.{ }^{-1}\right)$ 3396, 2932, 1653, 1542, 1374, 1116, 1054, 915

(see Figure SI-2b); Hydrodynamic radius (27.0 nm in water, $0.3 \mathrm{mg} / \mathrm{mL}$, see Figure SI-3b); $\mathrm{M}_{\mathrm{w}}$ 72530; Anal. Calcd. for $\left(\mathrm{C}_{12} \mathrm{H}_{20} \mathrm{~N}_{2} \mathrm{O}_{6}\right)_{\mathrm{n}}$ : C, 49.99; H, 6.99; N, 9.72. Found: C, 48.36; H, $6.96 ; \mathrm{N}, 9.82$.

\section{Conjugation of (4 $\alpha)$ to co-poly(MVK/DAPA) (2) to form GalNAc-conjugated} polymer (6)-A solution of $0.1 \%$ aqueous acetic acid $(2 \mathrm{~mL})$ was introduced into a $25-\mathrm{mL}$ flask containing co-poly(MVK/DAPA) (2) (18.6 mg, $0.174 \mathrm{mmol}$ based on carbonyl number) and compound $\mathbf{4 \alpha}(80.1 \mathrm{mg}, 0.339 \mathrm{mmol})$. After $4 \mathrm{~d}$ at $95^{\circ} \mathrm{C}$, the reaction mixture was cooled to rt, dialyzed in water to remove excess compound $4 \boldsymbol{\alpha}$, neutralized with Dowex 50WX8-100 resin and lyophilized to afford $\mathbf{6}$ as a fluffy white solid. ${ }^{1} \mathrm{H}-\mathrm{NMR}\left(\mathrm{D}_{2} \mathrm{O}, \delta / \mathrm{ppm}\right.$, see Figure SI-4b); IR (KBr, cm ${ }^{-1}$ ) 3398, 2932, 1655, 1542, 1375, 1119, 1054 (see Figure SI-5b); Hydrodynamic radius (27.4 $\mathrm{nm}$ in water, $0.3 \mathrm{mg} / \mathrm{mL}$, see Figure SI-6b); $\mathbf{M}_{\mathrm{W}} 102880$; Anal. Calcd. for $\left(\mathrm{C}_{11.24} \mathrm{H}_{19.24} \mathrm{~N}_{2.00} \mathrm{O}_{5.05}\right)_{\mathrm{n}}$ : C, 51.29; H, 7.37; N, 10.64. Found: C, 50.77; H, 7.36; $\mathrm{N}, 10.82$.

\section{Conjugation of (4 $\alpha)$ to co-poly(IMK/DAPA) (3) to form GalNAc-conjugated}

polymer (7)-A solution of $0.1 \%$ aqueous acetic acid $(2 \mathrm{~mL})$ was introduced into a $25-\mathrm{mL}$ flask containing co-poly(IMK/DAPA) (3) $(19.1 \mathrm{mg}, 0.165 \mathrm{mmol}$ based on carbonyl number) and compound $4 \boldsymbol{\alpha}(110 \mathrm{mg}, 0.466 \mathrm{mmol})$. After $7 \mathrm{~d}$ at $95^{\circ} \mathrm{C}$, the reaction mixture was allowed to cool to rt, dialyzed in water to remove excess compound $\mathbf{4 \alpha}$, neutralized with Dowex 50WX8 -100 resin and lyophilized to afford 7 as a fluffy white solid. ${ }^{1} \mathrm{H}-\mathrm{NMR}\left(\mathrm{D}_{2} \mathrm{O}, \delta / \mathrm{ppm}\right.$, see Figure SI-7b); IR (KBr, cm ${ }^{-1}$ ) 3436, 2956, 2925, 1653, 1559, 1458, 1375, 1117(see Figure SI-8b); Hydrodynamic radius ( $32.5 \mathrm{~nm}$ in water, $0.3 \mathrm{mg} / \mathrm{mL}$, see Figure SI-9b); $\mathbf{M}_{\mathrm{w}} 85630$; Anal. Calcd. for $\left(\mathrm{C}_{12.15} \mathrm{H}_{20.98} \mathrm{~N}_{2.00} \mathrm{O}_{5.15}\right)_{\mathrm{n}}$ : $\mathrm{C}, 52.59 ; \mathrm{H}, 7.62 ; \mathrm{N}, 10.10$. Found: $\mathrm{C}, 51.27 ; \mathrm{H}$, $7.53 ; \mathrm{N}, 10.28$.

$\mathbf{C}_{\mathbf{1 8}}$-Azobis(4-cyanovaleric acid) (8)-To a solution of 4,4'-azobis(4-cyanovaleric acid) (590 mg, $2.11 \mathrm{mmol})$ in $\mathrm{CH}_{2} \mathrm{Cl}_{2}$ (100 mL) was added 4-(dimethylamino)pyridine (260 mg, $2.11 \mathrm{mmol})$, triethylamine $(1.20 \mathrm{~mL}, 8.61 \mathrm{mmol})$, and octadecylamine $(2.27 \mathrm{~g}, 8.44 \mathrm{mmol})$. The solution was stirred for $15 \mathrm{~min}$ and $N$-(3-dimethylaminopropyl)- $N$ '-ethylcarbodiimide hydrochloride $(1.62 \mathrm{~g}, 8.44 \mathrm{mmol})$ was added. The solution was stirred in the dark for $18 \mathrm{~h}$ under $\mathrm{N}_{2}$, diluted with $\mathrm{CH}_{2} \mathrm{Cl}_{2}$, and washed with brine $(250 \mathrm{~mL})$ and water $(250 \mathrm{~mL})$. The organic layer was dried over $\mathrm{Na}_{2} \mathrm{SO}_{4}$, filtered and concentrated in vacuo. The resulting solid was purified on a silica gel column (hexanes:ethyl acetate, 2:1) to afford compound $\mathbf{8}(980 \mathrm{mg}$, 59\%) as a white solid. $\mathrm{mp}=102-104{ }^{\circ} \mathrm{C}$; IR (thin film): 2916, 2848, 2026, 1614, 1520, 1398, $776 \mathrm{~cm}^{-1} ;{ }^{1} \mathrm{H} \mathrm{NMR}\left(400 \mathrm{MHz}, \mathrm{CDCl}_{3}\right): \delta 0.80(\mathrm{t}, 6 \mathrm{H}, J=6.3), 1.49(\mathrm{t}, 6 \mathrm{H}, J=6.8), 1.67$ $-1.76(\mathrm{~m}, 31 \mathrm{H}), 1.78-1.81(\mathrm{~m}, 6 \mathrm{H}), 2.13-2.23(\mathrm{~m}, 6 \mathrm{H}), 2.40-2.49(\mathrm{~m}, 18 \mathrm{H}), 3.20-3.27(\mathrm{~m}$, $12 \mathrm{H}), 5.74-5.77(\mathrm{~m}, 4 \mathrm{H}), 5.93-5.95(\mathrm{~m}, 2 \mathrm{H}) ;{ }^{13} \mathrm{C} \mathrm{NMR}\left(100 \mathrm{MHz}, \mathrm{CDCl}_{3}\right): \delta$ 14.09, 22.66, 26.91, 29.33, 29.45, 29.55, 29.67, 31.89, 39.80, 72.56, 171.64; HRMS(FAB): Calcd. for $\mathrm{C}_{48} \mathrm{H}_{91} \mathrm{LiN}_{6} \mathrm{O}_{2}[\mathrm{M}+\mathrm{Li}]^{+}$783.7203, found 783.7197. Anal. Calcd. for $\mathrm{C}_{49} \mathrm{H}_{93} \mathrm{~N}_{6} \mathrm{O}_{3} \cdot \mathrm{H}_{2} \mathrm{O}: \mathrm{C}$, 73.54; H 11.71; N, 8.75; found C, 73.72; H, 11.97; N, 8.66.

$\mathbf{C}_{\mathbf{1 8}}$-poly(MVK) (10)-Anhydrous $p$-dioxane $(0.56 \mathrm{~mL})$ was introduced into a $10 \mathrm{~mL}$ Schlenk tube containing methyl vinyl ketone $(0.56 \mathrm{~mL}, 6.73 \mathrm{mmol})$ and $8(50 \mathrm{mg}, 0.064 \mathrm{mmol})$ under $\mathrm{N}_{2}$. The reaction mixture was stirred for $72 \mathrm{~h}$ at $95^{\circ} \mathrm{C}$ after degassing by four freeze-pump- 
thaw cycles. The reaction mixture was allowed to cool to rt, diluted with $p$-dioxane $(5 \mathrm{~mL})$, and added dropwise to excess diethyl ether $(1 \mathrm{~L})$ with vigorous stirring. The precipitate was filtered, washed with diethyl ether and dried in vacuo overnight to afford $\mathbf{1 0}$ as a white solid (325 mg). IR (thin film): 2926, 1709, 1426, 1356, 1239, 1163, 1109, $734 \mathrm{~cm}^{-1} ;{ }_{1}^{1} \mathrm{H}$ NMR (400 $\mathrm{MHz}, \mathrm{CDCl}_{3}, \delta / \mathrm{ppm}$, see Figure SI-11); GPC (THF eluent, polystyrene standard), $\mathrm{M}_{\mathrm{w}}=2.18$ $\times 10^{5} \mathrm{Da}, \mathrm{PDI}=2.20$; Anal. Calcd. for $\left(\mathrm{C}_{4} \mathrm{H}_{6} \mathrm{O}\right)_{\mathrm{n}}: \mathrm{C}, 68.54 ; \mathrm{H}, 8.63$; found $\mathrm{C}, 67.98 ; \mathrm{H}, 8.93$.

Cholesterol-poly(MVK) (11)—Anhydrous toluene $(0.56 \mathrm{~mL})$ was introduced into a $10 \mathrm{~mL}$ Schlenk tube containing methyl vinyl ketone $(0.56 \mathrm{~mL}, 6.7 \mathrm{mmol})$ and $9(50 \mathrm{mg}, 0.064 \mathrm{mmol})$ under $\mathrm{N}_{2}$. The reaction mixture was stirred for $72 \mathrm{~h}$ at $95^{\circ} \mathrm{C}$ after degassing by four freezepump-thaw cycles. The reaction mixture was allowed to cool to rt, diluted with toluene $(5 \mathrm{~mL})$, and then added dropwise to excess diethyl ether $(1 \mathrm{~L})$ with vigorous stirring. The precipitate was filtered and washed with diethyl ether then dried overnight in vacuo to afford $\mathbf{1 1}$ as a white solid (450 mg). IR (thin film): 3400, 2932, 1708, 1425, 1356, 1240, 1163, 958, $734 \mathrm{~cm}^{-1} ;{ }^{1} \mathrm{H}$ NMR (400 MHz, $\mathrm{CDCl}_{3}, \delta / \mathrm{ppm}$, see Figure SI-12); GPC (THF eluent, polystyrene standard), $\mathrm{M}_{\mathrm{w}}=1.71 \times 10^{5} \mathrm{Da}, \mathrm{PDI}=1.77$; Anal. Calcd. for $\left(\mathrm{C}_{4} \mathrm{H}_{6} \mathrm{O}\right)_{\mathrm{n}}: \mathrm{C}, 68.54 ; \mathrm{H}, 8.63$; found C, 69.98; $\mathrm{H}, 7.91$.

a-Aminooxy GalNAc $\mathbf{C}_{\mathbf{1 8}}$-poly(MVK) (12)-To a solution of $\mathbf{1 0}(3.0 \mathrm{mg}, 0.043 \mathrm{mmol}$ based on carbonyl number) in THF $(3 \mathrm{~mL})$ and $\mathrm{H}_{2} \mathrm{O}(1 \mathrm{~mL})$ was added $4 \boldsymbol{\alpha}(28 \mathrm{mg}, 0.120 \mathrm{mmol})$ and acetic acid $(5 \mu \mathrm{L})$. The reaction mixture was stirred at $95^{\circ} \mathrm{C}$ for $24 \mathrm{~h}$, allowed to cool to $\mathrm{rt}$ and concentrated in vacuo. The resulting solid was dissolved in $\mathrm{H}_{2} \mathrm{O}(4 \mathrm{~mL})$ and heated to reflux for $48 \mathrm{~h}$. The reaction mixture was cooled to rt, dialyzed in $\mathrm{H}_{2} \mathrm{O}$ and lyophilized to give 12 (12 mg, 87\% carbonyls reacted) as a fluffy white solid. IR (KBr) 3435, 1641, 1384, 1013, $664,576 \mathrm{~cm}^{-1}$; ${ }^{1} \mathrm{H}$ NMR (400 MHz, $\mathrm{D}_{2} \mathrm{O}$, $\delta / \mathrm{ppm}$, see Figure SI-13); GPC $\left(\mathrm{H}_{2} \mathrm{O}\right.$ eluent, polysaccharide standard), $\mathrm{M}_{\mathrm{w}}=30.0 \times 10^{3} \mathrm{Da}$, $\mathrm{PDI}=2.80$; Anal. Calcd. for $\left(\mathrm{C}_{12} \mathrm{H}_{20} \mathrm{~N}_{2} \mathrm{O}\right)_{\mathrm{n}}$ : C, 49.99; H, 6.99; N, 9.82; found: C, 47.04; H, 7.71; N, 7.82.

a-Aminooxy GalNAc Cholesterol-poly(MVK) (13)—To a solution of 11 (3.0 mg, 0.043 mmol based on carbonyl number) in THF $(3 \mathrm{~mL})$ and $\mathrm{H}_{2} \mathrm{O}(1 \mathrm{~mL})$ was added $\mathbf{4} \boldsymbol{\alpha}(28 \mathrm{mg}, 0.12$ $\mathrm{mmol})$ and acetic acid $(5 \mu \mathrm{L})$. The solution was heated to $95^{\circ} \mathrm{C}$, stirred for $24 \mathrm{~h}$ and concentrated in vacuo. The resulting solid was dissolved in $\mathrm{H}_{2} \mathrm{O}(4 \mathrm{~mL})$ and heated at reflux for $48 \mathrm{~h}$. The reaction mixture was cooled to rt, dialyzed in $\mathrm{H}_{2} \mathrm{O}$ and lyophilized to give $\mathbf{1 3}$ (11 mg, 80\% of carbonyls reacted) as a fluffy white solid. IR (KBr) $3483,1658,1641,1005,565 \mathrm{~cm}^{-1} ;{ }^{1} \mathrm{H}$ NMR (400 MHz, $\mathrm{D}_{2} \mathrm{O}, \delta / \mathrm{ppm}$, see Figure SI-14); GPC ( $\mathrm{H}_{2} \mathrm{O}$ eluent, polysaccharide standard), $\mathrm{M}_{\mathrm{w}}=30.9 \times 10^{3} \mathrm{Da}$, PDI = 3.18; Anal. Calcd. for $\left(\mathrm{C}_{12} \mathrm{H}_{20} \mathrm{~N}_{2} \mathrm{O}\right)_{\mathrm{n}}: \mathrm{C}, 49.99 ; \mathrm{H}, 6.99 ; \mathrm{N}, 9.82$; found: C, 50.79; H, 7.98; N, 6.56 .

a-Aminooxy GalNAc-Texas Red $\mathbf{C}_{\mathbf{1 8}}$-poly(MVK) (14)—To a solution of $\mathbf{1 0}$ (6 mg, 0.09 mmol based on carbonyl number) in THF $(5 \mathrm{~mL})$ and $\mathrm{H}_{2} \mathrm{O}(2 \mathrm{~mL})$ was added $\mathbf{4} \boldsymbol{\alpha}(40 \mathrm{mg}, 0.170$ $\mathrm{mmol})$, Texas Red hydrazide (5 $\mathrm{mg}, 8 \mu \mathrm{mol})$ and acetic acid $(5 \mu \mathrm{L})$. The reaction mixture was stirred for $24 \mathrm{~h}$ at $95^{\circ} \mathrm{C}$, allowed to cool to rt and concentrated in vacuo. The resulting solid was dissolved in $\mathrm{H}_{2} \mathrm{O}(7 \mathrm{~mL})$ and heated to reflux for $48 \mathrm{~h}$. The reaction mixture was cooled to rt, dialyzed in $\mathrm{H}_{2} \mathrm{O}$ and lyophilized to give $\mathbf{1 4}$ ( $21 \mathrm{mg}, 77 \%$ of carbonyls reacted) as a fluffy dark red solid. IR (KBr) 3434, 1658, 1641, 1381, 1005, 557, $463 \mathrm{~cm}^{-1} ;{ }^{1} \mathrm{H}$ NMR $(400 \mathrm{MHz}$, $\mathrm{D}_{2} \mathrm{O}, \delta / \mathrm{ppm}$, see Figure SI-15); GPC $\left(\mathrm{H}_{2} \mathrm{O}\right.$ eluent, polysaccharide standard $), \mathrm{M}_{\mathrm{w}}=30.9 \times$ $10^{3} \mathrm{Da}, \mathrm{PDI}=2.56$.

ACVA-PFP ester (15)—To a solution of 4,4'-azobis(4-cyanovaleric acid) (500 mg, 1.78 mmol) in $\mathrm{CH}_{2} \mathrm{Cl}_{2}(15 \mathrm{~mL})$ was added $N, N$-diisopropylethylamine $(745 \mu \mathrm{L}, 4.28 \mathrm{mmol})$ and pentafluorophenyl trifluoroacetate $(740 \mu \mathrm{L}, 4.29 \mathrm{mmol})$. The solution was stirred at $\mathrm{rt}$ for $6 \mathrm{~h}$ and evaporated to dryness. The resulting oil was purified by silica gel chromatography $(8: 1$ 
hexanes:ethyl acetate) to afford $\mathbf{1 5}$ as mixture of isomers (274 mg, 25\%). IR (thin film): 1796, 1514, 1390, 1296, 1094, 1052, $992 \mathrm{~cm}^{-1}$; ${ }^{1} \mathrm{H}$ NMR (400 MHz, CDCl $): \delta 1.72(\mathrm{~s}, 3 \mathrm{H}), 1.85$ (s, $6 \mathrm{H}), 2.48-2.64(\mathrm{~m}, 3 \mathrm{H}), 2.65-2.72(\mathrm{~m}, 3 \mathrm{H}), 2.74-2.88(\mathrm{~m}, 3 \mathrm{H}), 2.92-3.04(\mathrm{~m}, 3$ $\mathrm{H}) ;{ }^{13} \mathrm{C}$ NMR $\left(100 \mathrm{MHz}, \mathrm{CDCl}_{3}\right): \delta 23.66,23.88,28.23,28.32,32.69,32.75,71.60,71.73$, 116.99, 136.85, 138.50, 139.90, 141.75, 167.40; HRMS(FAB): Calcd. for $\mathrm{C}_{24} \mathrm{H}_{15} \mathrm{~F}_{10} \mathrm{~N}_{4} \mathrm{O}_{4}[\mathrm{M}$ $+\mathrm{H}]^{+}$613.0928, found 613.0933 .

Polymer (17)—To a solution of dipalmitoylphosphatidylethanolamine (DPPE) (25 mg, 0.036 mmol) in $\mathrm{MeOH}(1 \mathrm{~mL})$ and $\mathrm{CHCl}_{3}(3 \mathrm{~mL})$ was added $N, N$-diisopropylethylamine $(10 \mu \mathrm{L}$, $0.072 \mathrm{mmol})$ and $15(10 \mathrm{mg}, 0.016 \mathrm{mmol})$. The solution was stirred at $\mathrm{rt}$ for $2 \mathrm{~h}$ and evaporated to dryness. Anhydrous toluene $(0.5 \mathrm{~mL})$ and MVK $(140 \mu \mathrm{L}, 1.70 \mathrm{mmol})$ were added to the resulting oil. The reaction mixture was stirred for $72 \mathrm{~h}$ at $95^{\circ} \mathrm{C}$ after degassing by four freezepump-thaw cycles. The reaction mixture was allowed to cool to rt, diluted with $p$-dioxane (5 $\mathrm{mL}$ ), and then added dropwise to excess diethyl ether $(1 \mathrm{~L})$ with vigorous stirring. The precipitate was filtered, washed with diethyl ether and dried in vacuo overnight to afford $\mathbf{1 7}$ as a white solid (16 mg). IR (thin film): 2926, 1709, 1426, 1356, 1160, 1115, $734 \mathrm{~cm}^{-1} ;{ }^{1} \mathrm{H}$ NMR (400 MHz, $\mathrm{CDCl}_{3}$, $\delta / \mathrm{ppm}$, see Figure SI-16); GPC (THF eluent, polystyrene standard), $\mathrm{M}_{\mathrm{w}}=11.8 \times 10^{3} \mathrm{Da}, \mathrm{PDI}=1.31$; Anal. Calcd. for $\left(\mathrm{C}_{4} \mathrm{H}_{6} \mathrm{O}\right)_{\mathrm{n}}: \mathrm{C}, 68.54 ; \mathrm{H}, 8.63$; found C, 69.32; $\mathrm{H}, 8.50$.

GalNAc-conjugated Polymer (18)-To a solution of 17 (1.2 $\mathrm{mg}, 0.017 \mathrm{mmol}$ based on carbonyl number) in THF $(5 \mathrm{~mL})$ and $\mathrm{H}_{2} \mathrm{O}(2 \mathrm{~mL})$ was added $\mathbf{4} \boldsymbol{\alpha}(10 \mathrm{mg}, 0.042 \mathrm{mmol})$, Texas Red hydrazide $(1.0 \mathrm{mg}, 1.5 \mu \mathrm{mol})$ and acetic acid $(5 \mu \mathrm{L})$. The reaction mixture was stirred for $24 \mathrm{~h}$ at $95^{\circ} \mathrm{C}$, allowed to cool to rt and concentrated in vacuo. The resulting solid was dissolved in $\mathrm{H}_{2} \mathrm{O}(7 \mathrm{~mL})$ and heated to reflux for $48 \mathrm{~h}$. The reaction mixture was cooled to rt, dialyzed in $\mathrm{H}_{2} \mathrm{O}$ and lyophilized to give $\mathbf{1 8}$ (7 mg, $75 \%$ of carbonyls reacted) as a fluffy dark red solid. IR (KBr) 3450, 1641, 1631, 1378, 1015, 569, $463 \mathrm{~cm}^{-1}$; ${ }_{1}^{1} \mathrm{H}$ NMR (400 MHz, $\mathrm{D}_{2} \mathrm{O}$, $\delta / \mathrm{ppm}$, see Figure SI-17); GPC $\left(\mathrm{H}_{2} \mathrm{O}\right.$ eluent, polysaccharide standard $), \mathrm{M}_{\mathrm{w}}=65.7 \times 10^{3} \mathrm{Da}, \mathrm{PDI}=1.30$.

GalNAc-conjugated polymer (19)-To a solution of $\mathbf{1 7}(1.2 \mathrm{mg}, 0.017 \mathrm{mmol}$ based on carbonyl number) in THF $(5 \mathrm{~mL})$ and $\mathrm{H}_{2} \mathrm{O}(2 \mathrm{~mL})$ was added $\mathbf{4 \beta}(10 \mathrm{mg}, 0.042 \mathrm{mmol})$, texas red hydrazide $(1.0 \mathrm{mg}, 1.5 \mu \mathrm{mol})$ and acetic acid $(5 \mu \mathrm{L})$. The reaction mixture was stirred for $24 \mathrm{~h}$ at $95^{\circ} \mathrm{C}$, allowed to cool to $\mathrm{rt}$ and concentrated in vacuo. The resulting solid was dissolved in $\mathrm{H}_{2} \mathrm{O}(7 \mathrm{~mL})$ and heated to reflux for $48 \mathrm{~h}$. The reaction mixture was cooled to rt, dialyzed in $\mathrm{H}_{2} \mathrm{O}$ and lyophilized to give $\mathbf{1 9}$ (5 mg, 70\% of carbonyls reacted) as a fluffy dark red solid. IR (KBr) 3439, 1665, 1360, 1108, 1060, 963, $842 \mathrm{~cm}^{-1}$; ${ }_{1}^{1} \mathrm{H}$ NMR (400 MHz, $\mathrm{D}_{2} \mathrm{O}, \delta / \mathrm{ppm}$, see Figure SI-18); GPC $\left(\mathrm{H}_{2} \mathrm{O}\right.$ eluent, polysaccharide standard $), \mathrm{M}_{\mathrm{w}}=56.4 \times 10^{3} \mathrm{Da}$, PDI $=2.47$.

LacNAc-conjugated polymer (20)-To a solution of $\mathbf{1 7}(2.1 \mathrm{mg}, 0.029 \mathrm{mmol}$ based on carbonyl number) in THF $(5 \mathrm{~mL})$ and $\mathrm{H}_{2} \mathrm{O}(2 \mathrm{~mL})$ was added $\beta$-aminooxy- $N$-acetyllactosamine ( $17 \mathrm{mg}, 0.043 \mathrm{mmol})$, texas red hydrazide $(1.0 \mathrm{mg}, 1.5 \mu \mathrm{mol})$ and acetic acid (5 $\mu \mathrm{L})$. The reaction mixture was stirred for $24 \mathrm{~h}$ at $95{ }^{\circ} \mathrm{C}$, allowed to cool to rt and concentrated in vacuo. The resulting solid was dissolved in $\mathrm{H}_{2} \mathrm{O}(7 \mathrm{~mL})$ and heated to reflux for $48 \mathrm{~h}$. The reaction mixture was cooled to rt, dialyzed in $\mathrm{H}_{2} \mathrm{O}$ and lyophilized to give $\mathbf{2 0}(5 \mathrm{mg}, 60 \%$ of carbonyls reacted) as a fluffy dark red solid. IR (KBr) 3250, 2950, 1560, 1400, 1350, 1010, $980 \mathrm{~cm}^{-1} ;{ }^{1} \mathrm{H}$ NMR (400 MHz, $\mathrm{D}_{2} \mathrm{O}, \delta / \mathrm{ppm}$, see Figure SI-19); GPC $\left(\mathrm{H}_{2} \mathrm{O}\right.$ eluent, polysaccharide standard), $\mathrm{M}_{\mathrm{w}}=56.0 \times 10^{3} \mathrm{Da}, \mathrm{PDI}=2.03$.

Supported Lipid Bilayers ${ }^{19}$-Lipids were mixed in $\mathrm{CHCl}_{3}$ followed by evaporation of the organic solvent. The dried lipid films were hydrated in distilled, deionized water $(2 \mathrm{mg}$ lipid per $\mathrm{mL}$ ) at $4{ }^{\circ} \mathrm{C}$ for $12 \mathrm{~h}$. Small unilamellar vesicles (SUVs) were formed by repeated extrusion of the lipid suspension at $50{ }^{\circ} \mathrm{C}$ through poly-carbonate filters with $100 \mathrm{~nm}$ pores 
using a Lipex extruder. SUVs were mixed with phosphate buffered saline (PBS) solution to a final concentration of $0.4 \mathrm{mg}$ lipid / $\mathrm{mL}$ solution, and then incubated with clean glass cover slips for several minutes. Rupture of the vesicles with the substrate formed a continuous lipid bilayer, which was kept in PBS. The lipid membrane composition for experiments involving mucin mimic polymer incorporation was $95 \%$ mole\% DOPC (1,2-dioleoylsn-glycero-3phosphocholine) and 5\% DOTAP (1,2-dioleoyl-3-trimethylammonium-propane) (Avanti Polar Lipids, Alabaster, AL). For determination of lipid mobility, lipid membranes were composed of 94\% DOPC, 5.5\% DOTAP, and 0.5\% Texas Red DHPE (Texas Red 1,2dihexadecanoyl-sn-glycero-3-phosphoethanolamine) (Invitrogen, Carlsbad, CA).

Microscopy and florescence recovery after photobleaching-Images were obtained at rt using a Nikon TE300 inverted fluorescence microscope with a Hamamatsu ORCA 2 charge-coupled device camera and SIMPLE PCI acquisition software. Illumination was provided via a mercury arc lamp. The density of Texas Red-labeled mucin mimetic polymers was determined from fluorescence intensity values by comparison with the fluorescence from supported lipid bilayers with known densities of Texas Red-labeled lipids, under identical optical conditions. The relative densities of bound lectins were determined by measuring the fluorescence intensity of the lectins' FITC label; relative binding affinities were determined by normalizing the FITC intensity to the intensity of the Texas Red label of the incorporated polymers to account for variations in polymer density.

Molecular mobility was measured by examining Fluorescence Recovery after Photobleaching (FRAP). Fluorescent probes in a region defined by a partially closed aperture were bleached by intense illumination for $10 \mathrm{~s}$. Images were captured as mobile bleached and non-bleached fluorescent probes diffused among each other and were analyzed using custom software written with MATLAB (Mathworks, Natick, MA), described below, to extract the diffusion coefficient of the molecules. The local concentration $(C)$ of molecules with unbleached fluorophores is proportional to the fluorescence intensity $(I)$ at each pixel. (The background intensity, due mainly to read-out noise from the CCD camera, was measured and subtracted from each image, and the density of fluorophores is low enough, by over a factor of 10 , that non-linear selfquenching effects are negligible. Thus, $C$ is proportional to $I$.) The diffusing molecules were assumed to obey the statistical relations governing two-dimensional random walks, one of the consequences of which is that over a time increment $\Delta \mathrm{t}=\Delta \mathrm{x}^{2} / 2 D$, where $\Delta \mathrm{x}$ is the pixel size (the unit of our discrete measurement of $C$ ) and $D$ is the diffusion coefficient, the concentration at a given pixel becomes equal to the average of the concentration at its nearest neighbor pixels. To extract $D$ from a pair of fluorescence images, $I_{1}$ and $I_{2}$, separated in time by an amount $\Delta t$, the initial image $\left(I_{1}\right)$ was acquired and then subjected to and a series of nearest-neighbor averaging steps. At each step $(j)$, the resulting image $\left(I_{1}{ }^{\prime}\right)$ was compared with $I_{2}$, and their deviation was calculated $\left.\left(\chi^{2}(j)=\Sigma\left(I_{1}{ }^{\prime}-I_{2}\right)^{2}\right)\right)$. The $j$ that yields the minimal $\chi^{2}$ revealed the number of increments of $\Delta \mathrm{t}=\Delta \mathrm{x}^{2} / 2 D$ that occur in the time interval between the two images - i.e. $j \Delta \mathrm{x}^{2} /(2 D)=\Delta \mathrm{t}$, or $D=j \Delta \mathrm{x}^{2} /(2 \Delta \mathrm{t})$, providing $D$ in terms of experimental parameters. Notably, this method does not rely on assumptions about the shape of the bleached spot, or on precise measurements of the bleaching time, being sensitive only to differences between the two recorded images. Several pairs of images were used to deduce the $D$ values stated in the text; the uncertainty reported is the standard deviation. 28

\section{Supplementary Material}

Refer to Web version on PubMed Central for supplementary material. 


\section{ACKNOWLEDGMENT}

G.S.L was supported by a postdoctoral fellowship from the Korea Science \& Engineering Foundation (KOSEF). This research was supported by a grant to C.R.B from the National Institutes of Health (GM59907) and The Director, Office of Science, Office of Basic Energy Sciences, Division of Materials and Engineering, and the Office of Energy Biosciences of the U.S. Department of Energy under Contract No. DE-AC03-76SF00098. We thank Dr. Marian Snauko for helpful discussions and assistance with polymer characterization and Chris Harland for assistance with imaging bilayers.

\section{REFERENCES}

1. a Hang HC, Bertozzi CR. Bioorg. Med. Chem 2005;13:5021-5034. [PubMed: 16005634]Fukuda, M. Frontiers in Molecular Biology 30. In: Fukuda, M.; O. Hindsgaul, O., editors. Molecular and Cellular Glycobiology. Oxford Univ. Press; New York, NY: 2000. Chapter 1

2. Strous GJ, Dekker J. Crit. Rev. Biochem. Mol. Biol 1992;27:57-92. [PubMed: 1727693]

3. Rosen SD. Am. J. Pathol 1999;155:1013-1020. [PubMed: 10514381]

4. Hollingsworth MA, Swanson BJ. Nat. Rev. Cancer 2004;4:45-60. [PubMed: 14681689]

5. Gendler SJ, Spicer AP. Annu. Rev. Phys 1995;57:607-634.

6. a Coullerez G, Seeberber PM, Textor M. Macromol. Biosci 2006;6:634-647. [PubMed: 16881090] and references therein b Holland NB, Qui Y, Ruegsegger M, Marchant RE. Nature 1998;392:799801. [PubMed: 9572137]

7. Pratt MR, Bertozzi CR. Chem. Soc. Rev 2005;34:58-68. [PubMed: 15643490]and references therein

8. Macmillan D, Bertozzi CR. Angew. Chem. Int. Ed 2004;43:1355-1359.

9. Shogren R, Gerken TA, Jentoft N. Biochemistry 1989;28:5525-5536. [PubMed: 2775721]

10. Live DH, Williams LJ, Kuduk SD, Schwarz JB, Glunz PE, Chen X-T, Sames D, Kumar RA, Danishefsky SJ. Proc. Natl. Acad. Sci. U.S.A 1999;96:3489-3493. [PubMed: 10097062]

11. Lemieux GA, Bertozzi CR. Trends Biotechnol 1998;16:506-513. [PubMed: 9881482]

12. Marcaurelle LA; Shin Y, Goon S, Bertozzi CR. Org. Lett 2001;3:3691-3694. [PubMed: 11700114]

13. a Béraud V, Businelli L, Gnanou Y, Maillard B. Macromol. Rapid Commun 2000;21:901-904. b Spaether W, Klass K, Erker G, Zippel F, Fröhlich R. Chem. Eur. J 1998;4:1411-1417.

14. Nosjean O, Briolay A, Roux B. Biochim. Biophys. Acta 1997;1331:153-186. [PubMed: 9325440]

15. a Zhong X-D, Ishifune M, Nakao N, Yamashita N. J. Macromol. Sci.-Chem., Pure and Appl. Chem 1999;A36:287-303. b Tsuneka T, Ishifune M, Yamashita N. J. Macromol. Sci.-Chem., Pure and Appl. Chem 1994;A31:1169-1176. c Yamashita N, Ikezawa K, Ayukawa S-I, Maeshima T. J. Macromol. Sci.-Chem 1984;A21:615-629.

16. a Merle-Aubry L, Merle Y. Eur. Polymer J 1980;16:227-234. b Greenley RZ. J. Macromol. Sci.Chem 1980;A14:427-443. c Greenley RZ. J. Macromol. Sci.-Chem 1980;A14:445-515. d Lyons AR, Catterall E. Eur. Polymer. J 1971;7:839. e Lyons AR, Catterall E. Eur. Polymer. J 1971;7:849_ 862.

17. Molecular models were constructed using the MM2 energy minimization algorithm in CS Chem 3D Pro (Version 5.0).

18. a Winnik FM, Davidson AR, Hamer GK. Macromolecules 1992;25:1876-1880. b Sugiyama K, Shiraishi K, Matsumoto T. J. Polym. Sci., Part A: Polym. Chem 2003;41:1992-2000.

19. a Boxer SG. Curr. Opin. Chem. Biol 2000;4:704-709. [PubMed: 11102877] b Richter RP, Berat R, Brisson AR. Langmuir 2006;22:3497-505. [PubMed: 16584220]

20. Chen X, Lee GS, Zettl A, Bertozzi CR. Angew. Chem. Int. Ed 2004;43:6111-6116.

21. Chen X, Tam UC, Czlapinski JL, Lee GS, Rabuka D, Zettl A, Bertozzi CR. J. Am. Chem. Soc 2006;128:6292-6293. [PubMed: 16683774]

22. Rodriguez EC, Marcaurelle LA, Bertozzi CR. J. Org. Chem 1998;63:7134-7135. [PubMed: 11672350]

23. Axelrod D, Koppel DE, Schlessinger J, Elson E, Webb WW. Biophys. J 1976;16:1055-1069. [PubMed: 786399]

24. Sharon N. Adv. Immunol 1983;34:213-298. [PubMed: 6356810]

25. Sharon N, Lis H. J. Agric. Food Chem 2002;50:6586-6591. [PubMed: 12381156]

$J$ Am Chem Soc. Author manuscript; available in PMC 2008 September 15. 
26. De Boeck H, Loontiens FG, Lis H, Sharon N. Arch. Biochem. Biophys 1984;234:297-304. [PubMed: 6548353]

27. Fuster MM, Esko JD. Nat. Rev. Cancer 2005;5:526-42. [PubMed: 16069816]

28. Berg, HC. Random Walks in Biology. Princeton University Press; Princeton, NJ: 1993. Chapter 1 
A

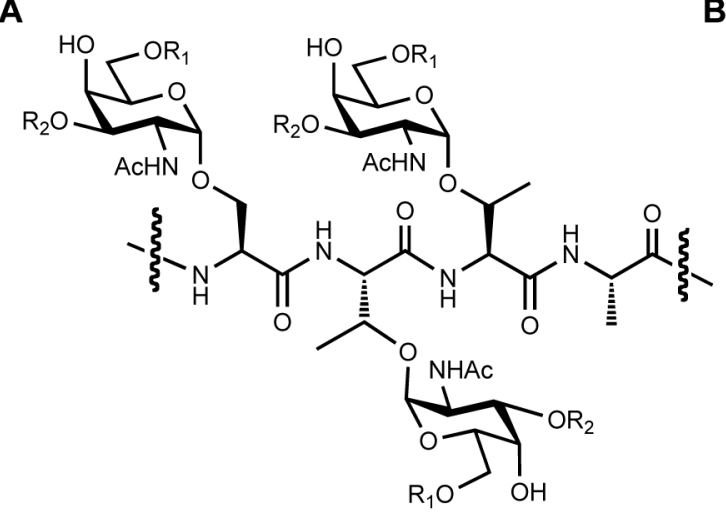

$\mathrm{R}_{1}, \mathrm{R}_{2}=$ oligosaccharides

C

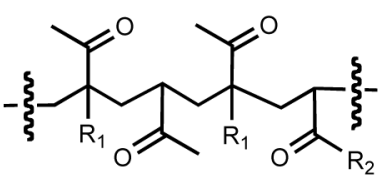<smiles>CCNCCCN(C)[N+](C)(C)CCCNCC</smiles>

B

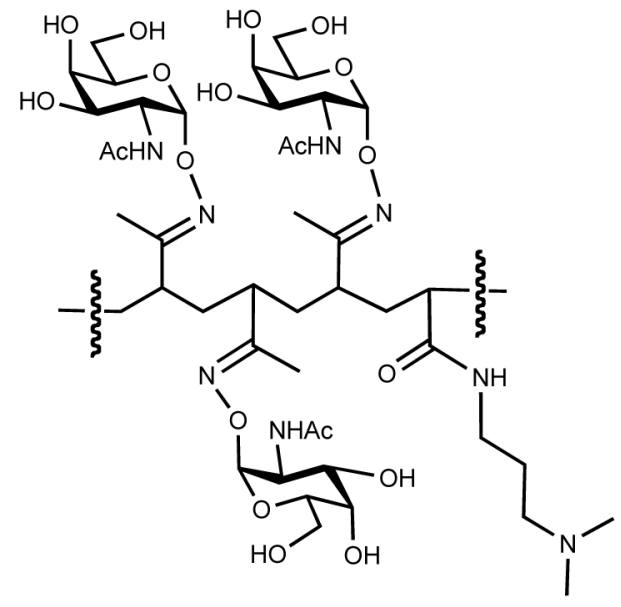

Figure 1.

Structures of native mucin segments from (A) the cell-surface protein CD43 and (B) a synthetic mucin mimic. The core GalNAc residue bound to Ser or Thr is often extended with additional sugars at $R^{1}$ and $R^{2}$. (C) Structures of polymer backbones and glycans employed in this study. 

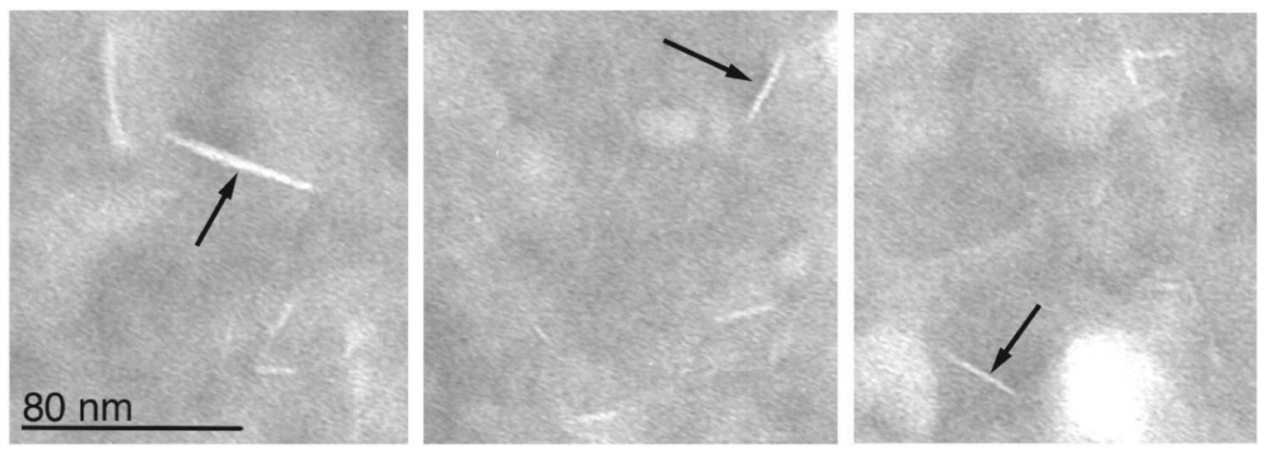

Figure 2.

Transmission electron micrographs of polymer 5 negatively stained with $1 \%$ phosphotungstic acid (PTA). The three panels are representative fields from the same carbon grid. Arrows indicate individual polymer molecules. 


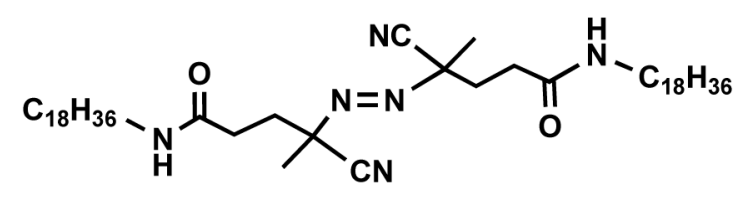

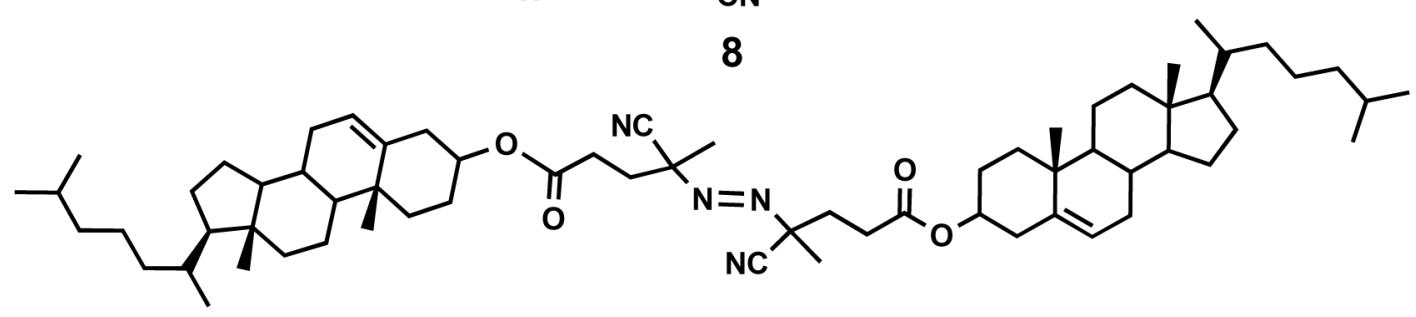

9

Figure 3.

End-functionalized free radical initiators. 

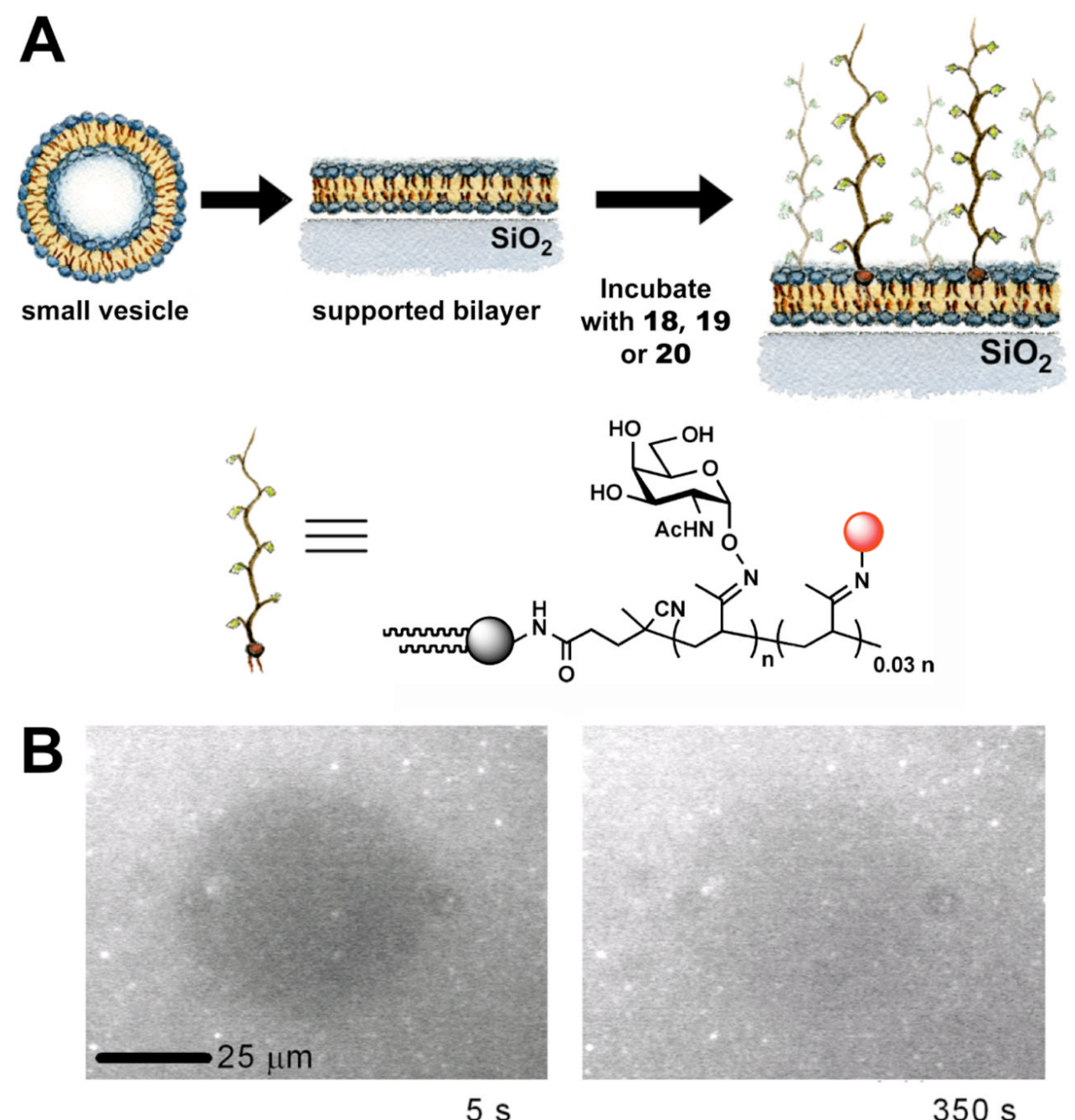

Figure 4.

A) Schematic of supported lipid bilayer formation from small liposomes, and polymer incorporation in a supported lipid bilayers. B) Fluorescence images of $\mathbf{1 8}$ incorporated into a supported lipid bilayer. Fluorescence recovery after photobleaching (FRAP) demonstrates the fluidity of the membrane-anchored mucin mimics. Left: fluorophores conjugated to the polymer were bleached in the central zone. Right: after 350 seconds, bleached and unbleached molecules have diffused, leading to recovery of the dark zone's fluorescence. Analysis revealed a diffusion coefficient identical to that of the membrane lipids. 


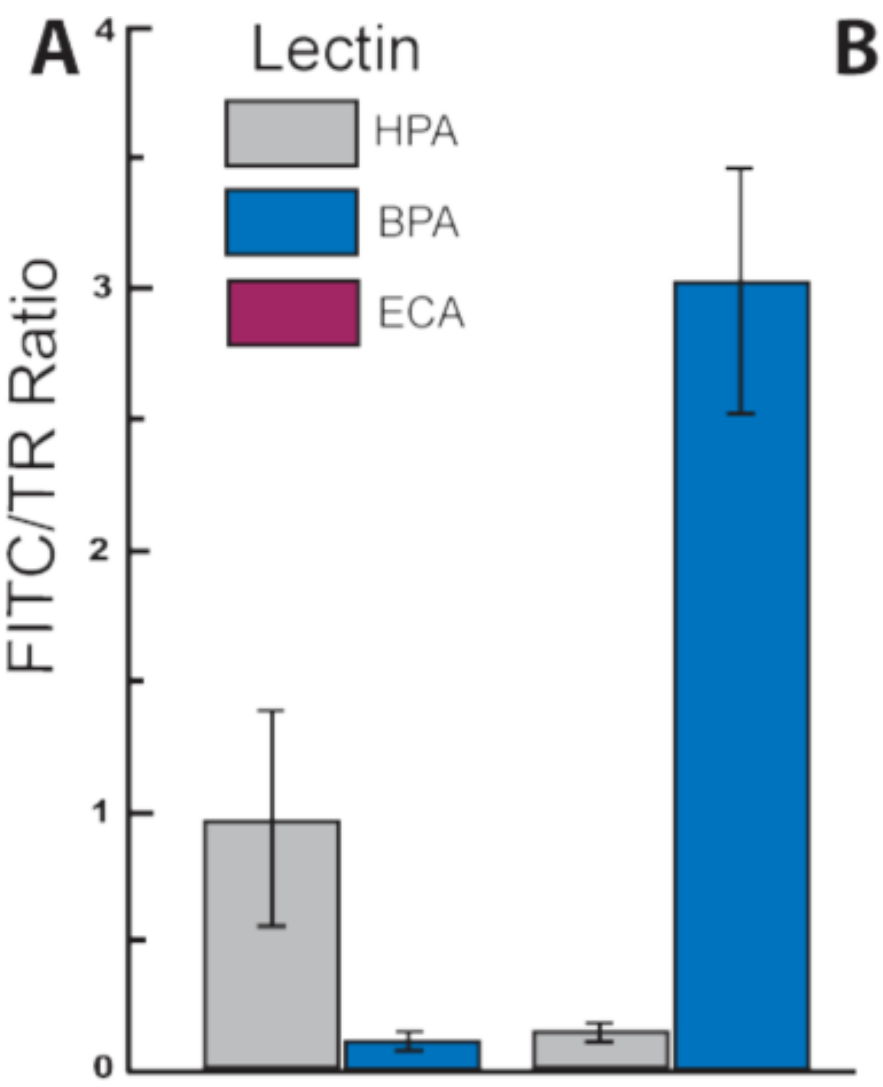

18

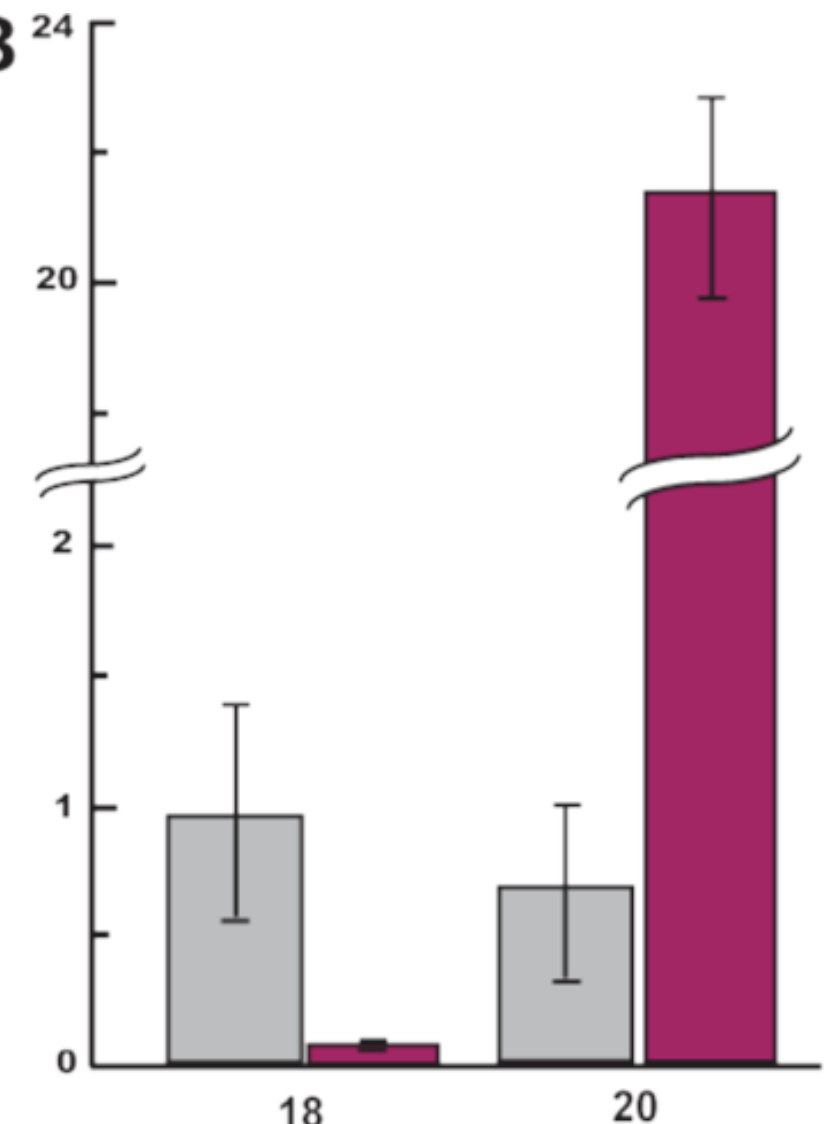

18

Figure 5.

A) Lectin binding to 18 or 19 displayed on supported bilayers. HPA exhibits a stronger binding to 18 ( $\alpha$-GalNAc) while BPA exhibits a stronger affinity for 19 ( $\beta$-GalNAc) B) Lectin binding to 18 or 20 displayed on supported bilayers. ECA exhibits a stronger affinity for 20 ( $\beta$-LacNAc). The carbohydrate specificities of the lectin bindings replicate those seen in natural biological systems. Error bars indicate the standard deviation for 3 replicate experiments. 


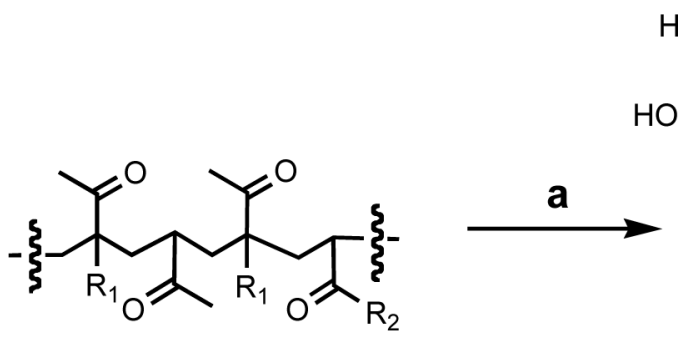

1-3

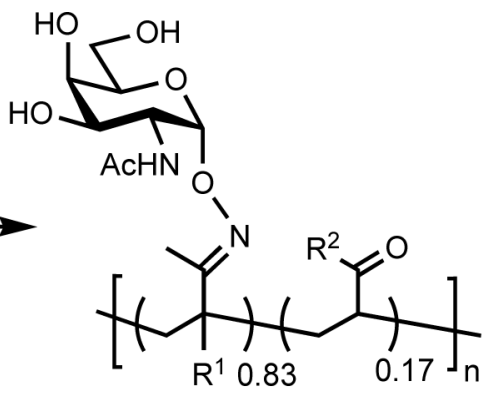

\begin{tabular}{l|lll} 
& $\mathrm{R}^{1}$ & $\mathrm{R}^{2}$ \\
\hline $\mathbf{1}$ and $\mathbf{5}$ & $\mathrm{H}$ & $\mathrm{H}$ & \\
$\mathbf{2}$ and $\mathbf{6}$ & $\mathrm{H}$ & $\mathrm{H}$ \\
$\mathbf{3}$ and $\mathbf{7}$ & $\mathrm{Me}$ &
\end{tabular}

Scheme 1. Synthesis of polymers functionalized with GalNAc residues ${ }^{\mathrm{a}}$

${ }^{a}$ Conditions: a) $\mathbf{4 \alpha}$ (2.8 equiv), $\mathrm{CH}_{3} \mathrm{Cl}: \mathrm{H}_{2} \mathrm{O}, \mathrm{AcOH}, 95^{\circ} \mathrm{C}$. 


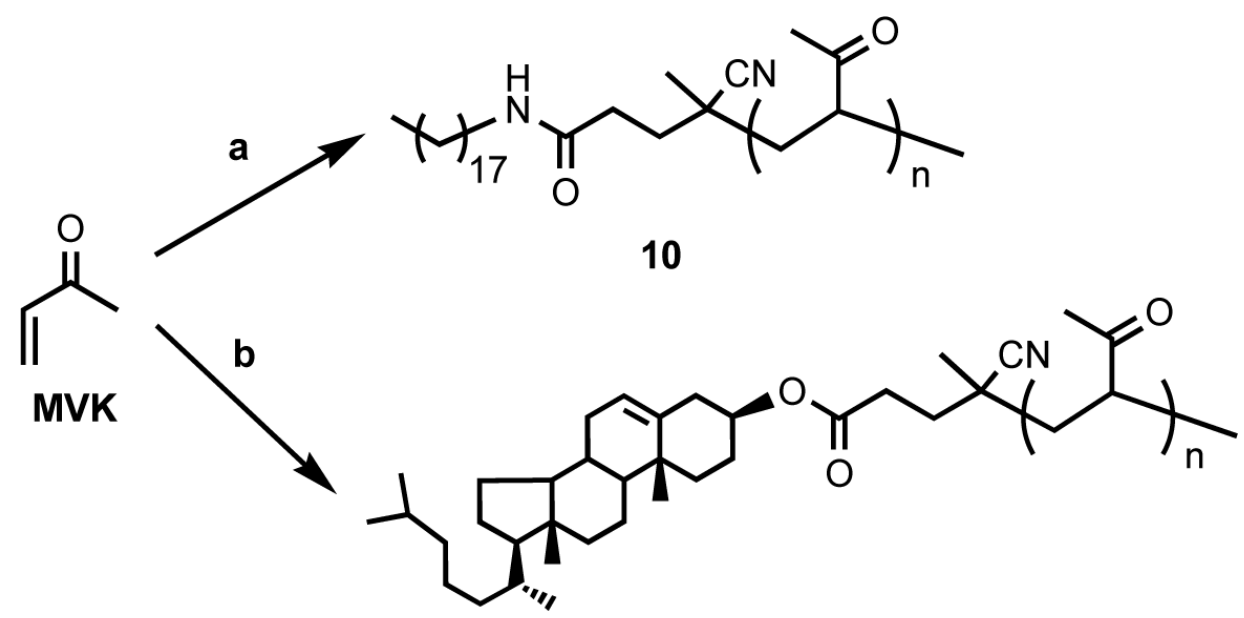

11

Scheme 2. Synthesis of end functionalized polymers ${ }^{b}$

${ }^{b}$ Conditions: a) 8, p-dioxane, $95{ }^{\circ} \mathrm{C}, 72 \mathrm{~h}$. b) 9 , toluene, $95^{\circ} \mathrm{C}, 72 \mathrm{~h}$. 


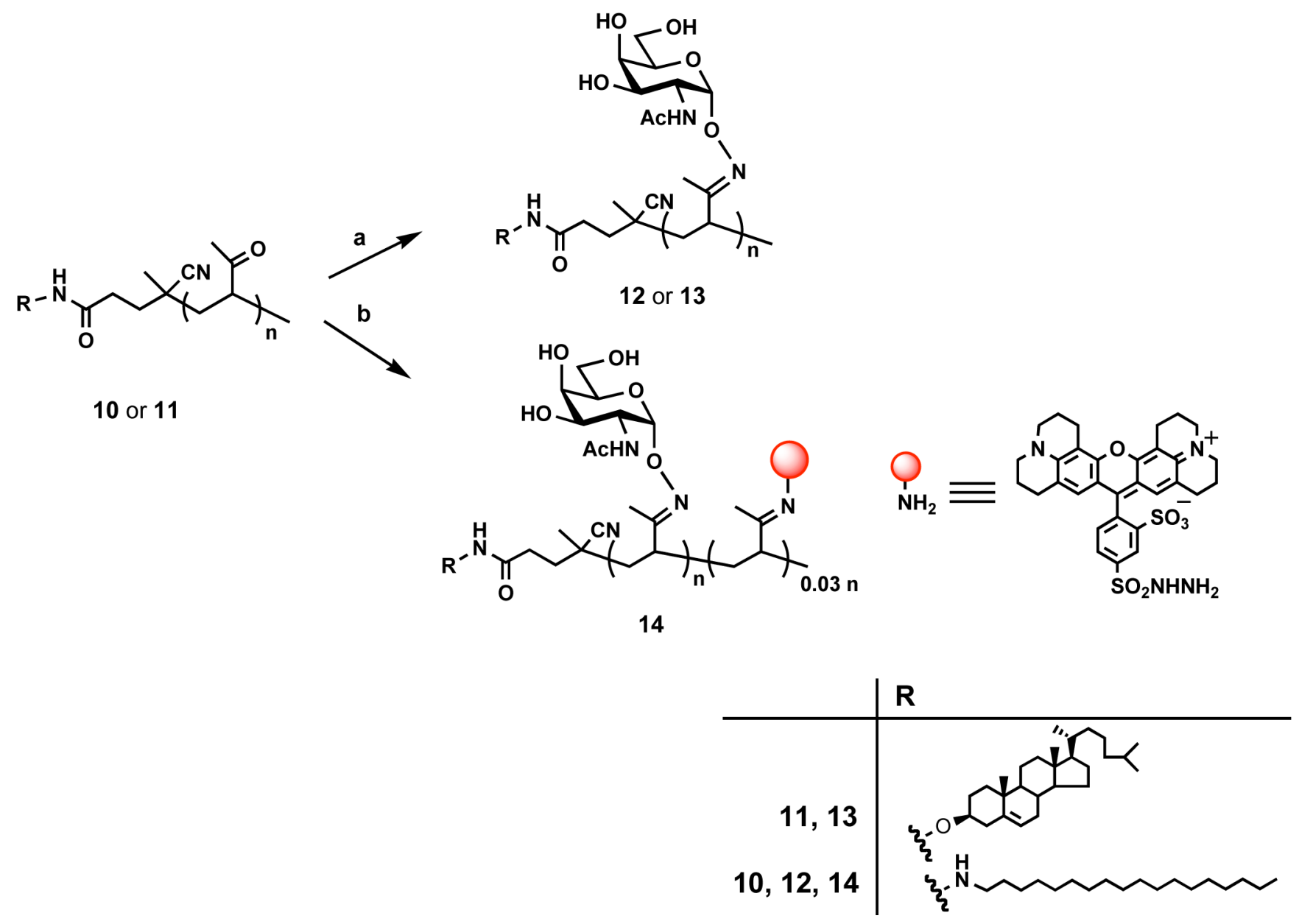

Scheme 3. Ligation of GalNAc derivatives to the poly ketone polymer backbone ${ }^{c}$

${ }^{c}$ Conditions: a) $\mathbf{4 \alpha}$ (2.8 equiv), $\mathrm{CH}_{3} \mathrm{CN}: \mathrm{H}_{2} \mathrm{O}$ (3:1), $\mathrm{AcOH}, 95^{\circ} \mathrm{C}$. b) $\mathbf{4 \beta}$ (2.8 equiv), Texas $\mathrm{Red}$ hydrazide (0.03 equiv), $\mathrm{CH}_{3} \mathrm{CN}: \mathrm{H}_{2} \mathrm{O}(3: 1), \mathrm{AcOH}, 95^{\circ} \mathrm{C}$. 


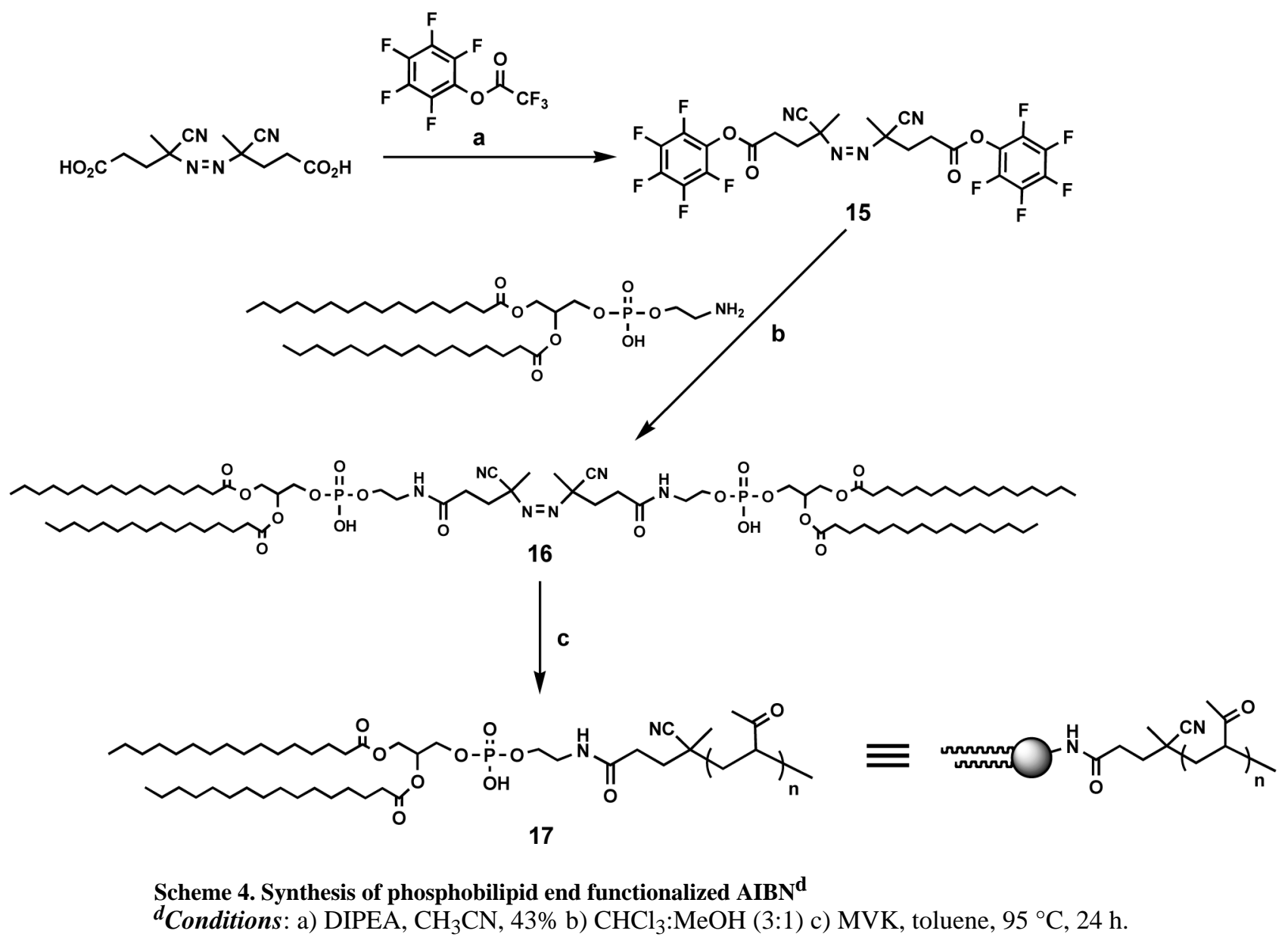

J Am Chem Soc. Author manuscript; available in PMC 2008 September 15. 

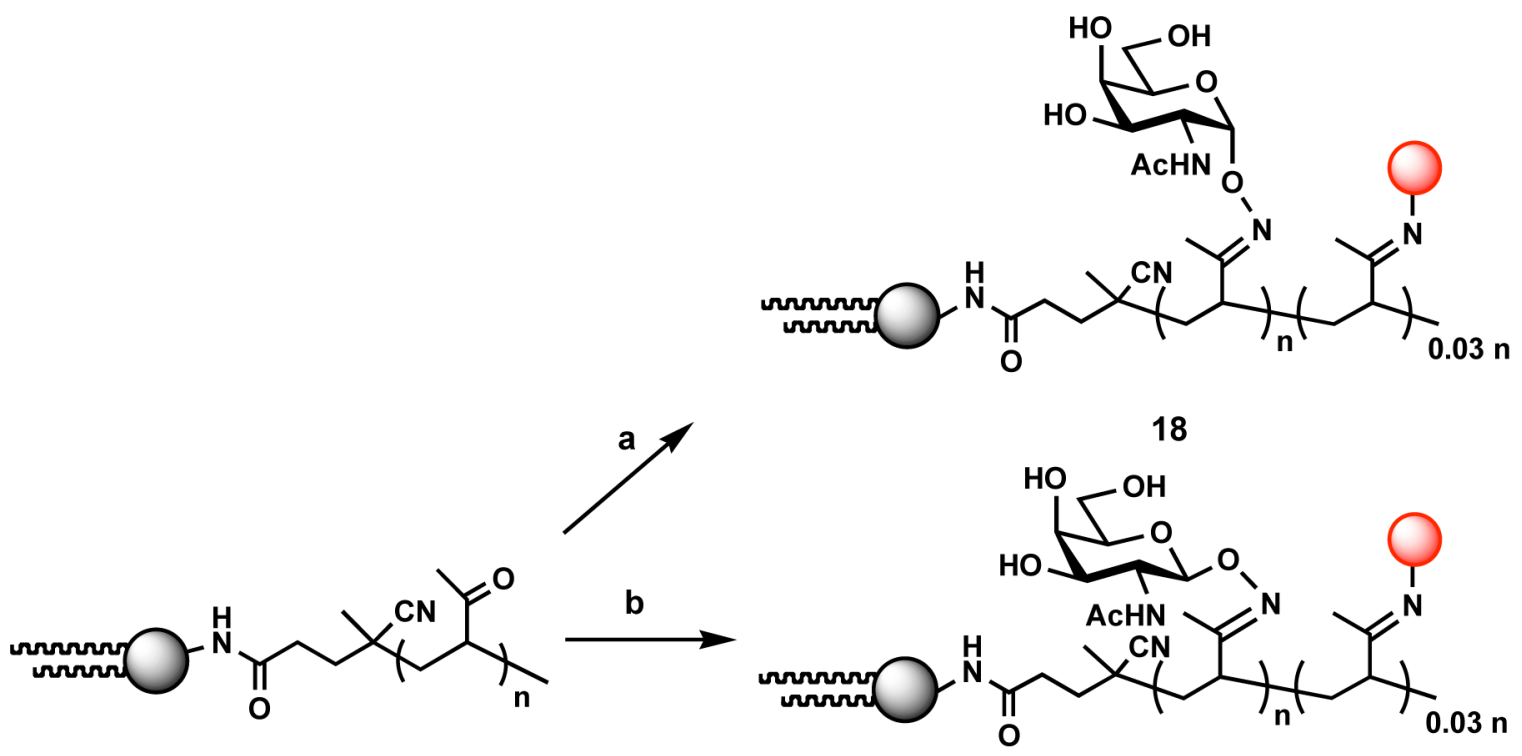

17

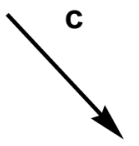

19

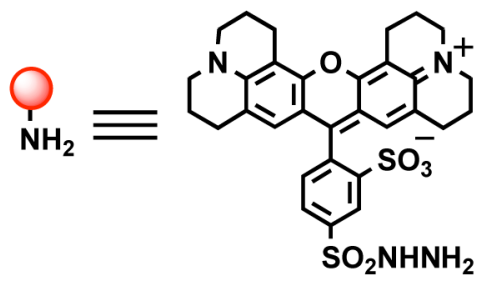

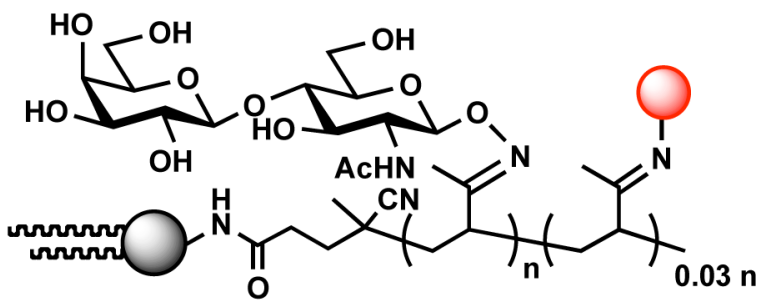

20

Scheme 5. Ligation of GalNAc derivatives and Texas Red hydrazide to the polymer backbone $\mathrm{e}^{\mathrm{e}}$ ${ }^{\boldsymbol{e}}$ Conditions: a) 4a, Texas Red hydrazide, $\mathrm{CH}_{3} \mathrm{CN}: \mathrm{H}_{2} \mathrm{O}$, $\mathrm{AcOH}, 95{ }^{\circ} \mathrm{C}$ b) $\mathbf{4 \beta}$, Texas Red hydrazide, $\mathrm{CH}_{3} \mathrm{CN}: \mathrm{H}_{2} \mathrm{O}, \mathrm{AcOH}, 95^{\circ} \mathrm{C}$ c) $\beta$-aminooxy LacNAc, Texas Red hydrazide, $\mathrm{CH}_{3} \mathrm{CN}: \mathrm{H}_{2} \mathrm{O}, \mathrm{AcOH}, 95^{\circ} \mathrm{C}$. 


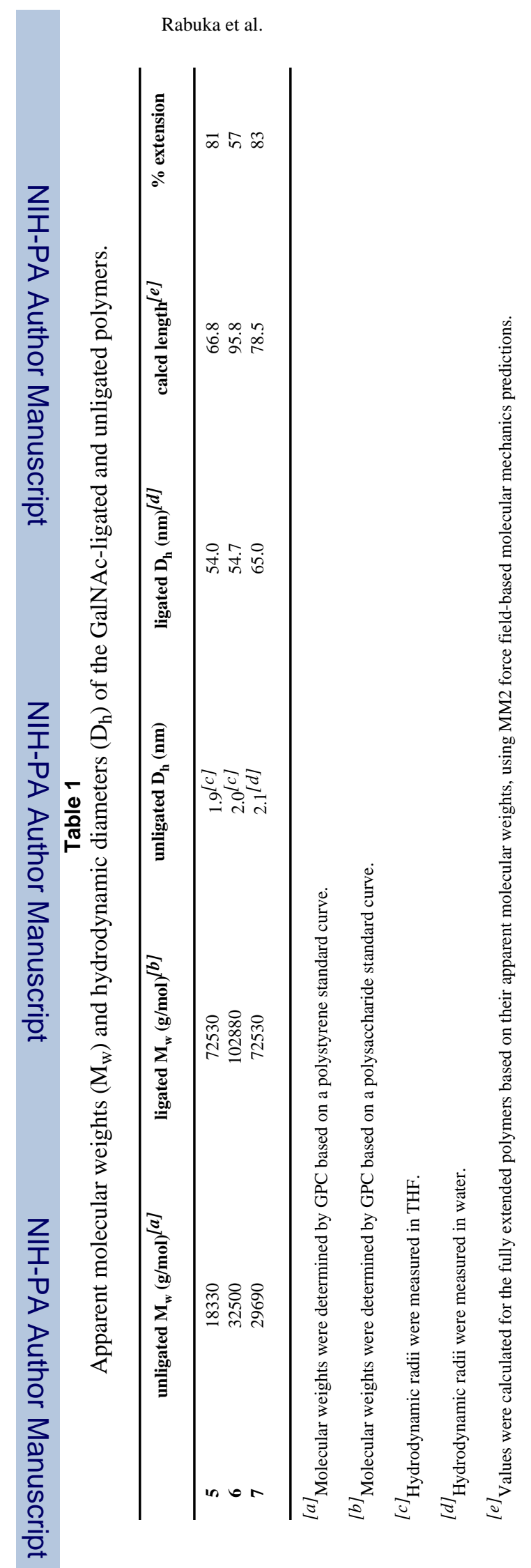

Page 23 